\title{
Analysis of wastewater facultative pond using advection-diffusion model based on explicit finite difference method
}

\author{
S. Sunarsih ${ }^{\dagger}$, Dwi Purwantoro Sasongko², S. Sutrisno ${ }^{1}$, Gitta Agnes Putri ${ }^{3}$, H.Hadiyanto ${ }^{4}$ \\ ${ }^{1}$ Department of Mathematics, Faculty of Science and Mathematics, Diponegoro University, Semarang, Indonesia, 50275 \\ ${ }^{2}$ Department of Physics, Faculty of Science and Mathematics, Diponegoro University, Semarang, Indonesia, 50275 \\ ${ }^{3}$ Graduate Student in the Department of Mathematics, Faculty of Science and Mathematics, Diponegoro University, Semarang, Indonesia, 50275 \\ ${ }^{4}$ Graduate Program of Environmental Science, School of Postgraduate Studies, Diponegoro University, Semarang, Indonesia, 50241
}

\begin{abstract}
This paper describes an advection-diffusion mathematical model in facultative ponds of different geometrical domains. The geometrical domains of the facultative ponds are the side (one-dimensional), the plane (two-dimensional), and the space (three-dimensional). The purpose of this paper is to know the numerical simulations of these three advection-diffusion models (1D, 2D, and 3D) using explicit finite difference method. Numerical simulation can be used to evaluate the distribution of pollutant concentrations. The concentration of pollutant tested was same as the concentration of biochemical oxygen demand. The result of numerical simulation showed that more complex the geometrical domain of a facultative pond, the more visible is the process of moving the mass concentration (advection) and mass spread (diffusion) in the facultative ponds.
\end{abstract}

Keywords: Advection-Diffusion Model, Explicit Finite Difference Method, Facultative Ponds, Numerical Simulation

\section{Introduction}

Healthy living is one of the basic needs of society that must be met. A healthy environment is defined as an environment free of water, air, or soil contamination. The stipulation for such an environment will be satisfied if the wastewater is managed properly. The environmental remains polluted if the wastewater is discharged without being processed. A responsible service policy and strategy for handling wastewater are required. In urban cities, a centralized wastewater management system has been established for this purpose. This management system prevents pollution from domestic wastewater by utilizing piping networks. Wastes are then processed in a wastewater treatment plant (WWTP).

A WWTP consists of six ponds, four facultative ponds and two maturation ponds. The facultative pond is capable of degrading the large amount of organic matter which resides in household waste water. The transport of pollutants through displacement and mass spread of substances takes place in facultative ponds. The transportation of a substance from one site to another is called advection [1]. The spread of particles due to random molecular motion is described by Fick's law as diffusion [2]. Diffusion is different from dispersion. The rate of spread of particles through diffusion is assumed to be proportional to the gradient of concentration of particle, while the rate of spread of particles through dispersion is different at different locations [3]. By knowing the pollutant gradient of the pond, a mathematical model can be constructed to describe the phenomena of transportation of pollutants. The pollutant gradient may be a straight line on one side of the pond (one-dimensional), may appear horizontally and vertically on the plane (two-dimensional), or may appear in space (three-dimensional). The advection-diffusion mathematical model is represented by using partial differential equations.

Biochemical oxygen demand (BOD) is the parameter which is used to determine the degradation efficiency of the dominant organic matter contained in household wastewater. The efficiency of degradation of organic matter in facultative ponds depends on the rate of decline in the BOD value [4]. BOD parameter is important for designing a wastewater treatment plant $[5,6]$. Some other important parameters are also used to analyze organic matter in wastewater. The use of dissolved oxygen (DO) parameter has been discussed by Noikondee
This is an Open Access article distributed under the terms of the Creative Commons Attribution Non-Commercial License (http://creativecommons.org/licenses/by-nc/3.0/) which permits unrestricted non-commercial use, distribution, and reproduction in any medium, provided the original work is properly cited.

Copyright (C) 2021 Korean Society of Environmental Engineers
Received December 12, 2019 Accepted June 17, 2020

${ }^{\dagger}$ Corresponding author

Email: narsih_pdil@yahoo.com

Tel: +62-8112995178 Fax: +62-247648-0922

ORCID: 0000-0002-5139-5829 
et al. [7]. Hence, analyzing these important parameters are important in wastewater management and optimization processes.

Various researches on advection-diffusion mechanisms have been conducted by using numerical solutions. Kaya et al. [8] compared four different numerical methods for solving advection-diffusion equations. These are finite difference, fourth-order finite difference, finite volume, and quadrature differential methods. Thongmoon et al. [9] also compared finite difference methods, such as the forward-time central-space (FTCS) method and the Crank-Nicholson method with the cubic spline scheme for solving the one-dimensional advection-diffusion equation. Savovic et al. [10] solved the one-dimensional advection-diffusion equation with the variable coefficients in semi-infinite media. Dehghan et al. [11] have constructed as well as compared several different numerical techniques with each other to solve a three-dimensional advection-diffusion equation with a constant coefficient. This technique is based on the two-level fully explicit and fully implicit finite difference approximations. In another work, Thongmoon et al. [12] have produced examples in which three-dimensional advection dispersion equations were solved using finite difference numerical methods, such as FTCS. Appadu et al. [13] addressed two forms of advection-diffusion problems through three different numerical methods, namely third-order and fourth-order upwind schemes as well as non-standard finite difference schemes.

Recently, some published research articles describe the superiority of finite difference method. Brewitt-Taylor et al. [14] discussed about the use of finite difference method for micro-perforated panel absorber predicting, whereas Patil et al. [15] applied the finite difference method to analyze bio-heat transfer in human breast cyst. Furthermore, Gao et al. [16] applied finite difference method for isotropic elastic wave simulations. Ben-romdhane [17] solved the Bratu's problem by using finite difference method. Arteaga et al. [18] showed that static diffusion equation model could be solved by using finite difference method. For more theories and further applications, the modified (generalized) finite difference method was investigated by some researchers, such as Kamyabi et al. [19]. This modified (generalized) finite difference method has been applied in many areas, such as in analyzing matched layer elements [20], solving plane crack problem [21], analyzing dendritic growth [22], numerical simulation on waves-current interactions [23], and analyzing three-dimensional transient electromagnetic problems [24].

Several authors, including Sunarsih et al. [25], have studied facultative ponds. Sunarsih et al. [26] created a mathematical model based on facultative stabilization ponds that tread domestic wastewater in steady conditions. In another work, Sunarsih et al. [27] formed 13 sets of nonlinear simultaneous differential equations to evaluate the functions of WWTPs. Furthermore, Sunarsih et al. [28, 29] applied finite difference numerical method and Dufort Frankel method to one- and two-dimensional chemical oxygen demand (COD) concentration model in waste stabilization ponds and in simulation of advection-diffusion on flow in waste stabilization ponds (1-dimension) with finite difference method forward time central-space scheme [30]. In addition, Sunarsih et al [31] also completed the two-dimensional advection dispersion model of BOD concentration by utilizing finite difference methods for validating it.

By deploying explicit finite difference methods based on the distribution of BOD concentration in facultative ponds in one-, two-, and three-dimensional domains, this article provides a numerical solution for the advection-diffusion model.

\section{Material and Methods}

\subsection{Facultative Ponds}

Facultative ponds are one of the ponds in WWTP. One such plant is located at Sewon, Bantul, D.I. Yogyakarta, Indonesia. The Sewon WWTP managed wastewater via centralized system. The network of sewage pipes carries wastewater from households in Sleman, Bantul, and Yogyakarta and drains it in the Sewon WWTP.

The biological processes inside the WWTP were conducted in facultative ponds which are designed to degrade (waste loads of $100-400 \mathrm{~kg}$ BOD per day at $20-25^{\circ} \mathrm{C}$ ). The largest source of oxygen in each pond comes from photosynthesis in algae and this oxygen is needed by the aerobic bacteria to degrade organic matter [4]. Therefore, waste loads are regulated to maintain the total population of algae in water.

Table 1. Water Quality Data for The Sewon WWTP in 2018

\begin{tabular}{|c|c|c|c|c|c|c|c|c|c|c|c|c|}
\hline \multirow{2}{*}{ Month } & \multicolumn{2}{|c|}{ pH } & \multicolumn{2}{|c|}{ TEMP $\left({ }^{\circ} \mathrm{C}\right)$} & \multicolumn{2}{|c|}{ DO (mg/L) } & \multicolumn{2}{|c|}{ BOD (mg/L) } & \multicolumn{2}{|c|}{ COD (mg/L) } & \multicolumn{2}{|c|}{ TSS (mg/L) } \\
\hline & IN & OUT & IN & OUT & IN & OUT & IN & OUT & IN & OUT & IN & OUT \\
\hline January & 6.20 & 6.05 & 28.93 & 29.75 & 1.10 & 3.02 & 202.15 & 21.45 & $1,587.52$ & 84.17 & 331.80 & 28.10 \\
\hline February & 6.00 & 6.10 & 28.70 & 29.38 & 1.48 & 3.45 & 153.05 & 23.25 & 925.18 & 102.26 & 268.90 & 21.90 \\
\hline March & 6.10 & 6.00 & 28.83 & 29.31 & 0.98 & 3.14 & 214.95 & 25.10 & $1,537.76$ & 114.66 & 290.90 & 23.57 \\
\hline April & 6.10 & 6.19 & 28.93 & 29.57 & 1.22 & 3.16 & 142,26 & 29.52 & 735.98 & 91.86 & 239.52 & 27.33 \\
\hline May & 6.03 & 7.56 & 29.30 & 15.22 & 2.13 & 2.28 & 222.33 & 27.40 & $1,533.10$ & 486.39 & 452.75 & 22.70 \\
\hline June & 6.09 & 6.14 & 28.36 & 28.66 & 1.30 & 3.27 & 214.23 & 21.68 & 928.12 & 76.78 & 296.36 & 24.91 \\
\hline July & 6.07 & 6.00 & 28.40 & 28.53 & 0.80 & 3.10 & 301.00 & 17.33 & $2,064.81$ & 52.04 & 492.33 & 26.33 \\
\hline August & 6.00 & 6.00 & 28.32 & 28.55 & 0.71 & 3.09 & 310.41 & 27.86 & $1,468.13$ & 70.91 & 714.18 & 29.59 \\
\hline September & 5.95 & 6.00 & 28.71 & 29.26 & 0.4 & 2.95 & 281.86 & 25.71 & $1,273.38$ & 125.11 & 637.95 & 36.86 \\
\hline October & 6.69 & 6.90 & 28.49 & 28.86 & 1.00 & 3.10 & 437.05 & 23.43 & $2,290.31$ & 113.56 & 541.43 & 25.19 \\
\hline November & 7.25 & 7.70 & 28.00 & 28.00 & 0.93 & 3.24 & 239.79 & 22.14 & 972.10 & 38.10 & 281.81 & 25.10 \\
\hline December & 7.32 & 7.71 & 27.55 & 28.08 & 1.69 & 3.17 & 261.15 & 24.58 & $1,073.66$ & 97.49 & 261.89 & 24.58 \\
\hline
\end{tabular}


Table 2. Influent Data for the Sewon WWTP in 2018

\begin{tabular}{lcccc}
\hline \multirow{2}{*}{ Month } & \multicolumn{4}{c}{ Volume $\mathbf{( m}^{\mathbf{3}} \mathbf{)}$} \\
\cline { 2 - 5 } & Minimum & Maximum & Average & Total \\
\hline January & 215 & 11,815 & 5,820 & 180,433 \\
February & 1,086 & 19,910 & 7,839 & 227,325 \\
March & 2,739 & 13,308 & 8,636 & 250,453 \\
April & 3,123 & 15,016 & 8,720 & 235,440 \\
May & 0 & 11,161 & 5,639 & 163,520 \\
June & 38 & 486 & 111 & 2,002 \\
July & 491 & 5,273 & 1,790 & 32,221 \\
August & 736 & 5,273 & 1,925 & 26,955 \\
September & 736 & 5.273 & 1,699 & 20,390 \\
October & 17 & 30 & 24 & 310 \\
November & 736 & 5,273 & 1,740 & 22,623 \\
December & 5,532 & 19,164 & 13,152 & 53,624 \\
\hline
\end{tabular}

The average BOD of treated water is $18 \mathrm{mg} / \mathrm{L}$ (cleaning ratio of $87 \%$ ), which is below the expected amount of $30 \mathrm{mg} / \mathrm{L}$. This meets the value stipulated by river drainage regulations for the Bedog river, which has a BOD less than $50 \mathrm{mg} / \mathrm{L}$. Water quality data for the Sewon WWTP in 2018 (yearly evaluation data for the WWTP) is cited in Table 1.

Influent from WWTPs tends to increase throughout the rainy season and during dry season. Storm can cause widespread structural damage to connections, increased roof drainage, and damage in pipes that raises the groundwater level. Influent from the Sewon WWTP in the year 2018 has been shown in Table 2 (yearly evaluation data for the WWTP).

\subsection{Advection-Diffusion Model}

The mass-balance equation of BOD in a pond flow consists of inflow, outflow, reaction, and deposition processes. However, in this case, the reaction and settlement mechanisms are not taken into account, because BOD was assumed not to undergo settlement and no reaction with any material in the flow.

By considering the geometrical domain, the advection-diffusion mechanism in a facultative pond can be described by a series of mathematical equations. The geometrical domain of a facultative pond consists of surface planes and interior space. The geometrical domains are shown in Fig. 1-3. Fig. 1 illustrates that water flow only occurs in one direction, namely $x$, so that advection occurs only in the $x$ direction, whereas diffusion can occur in all directions.

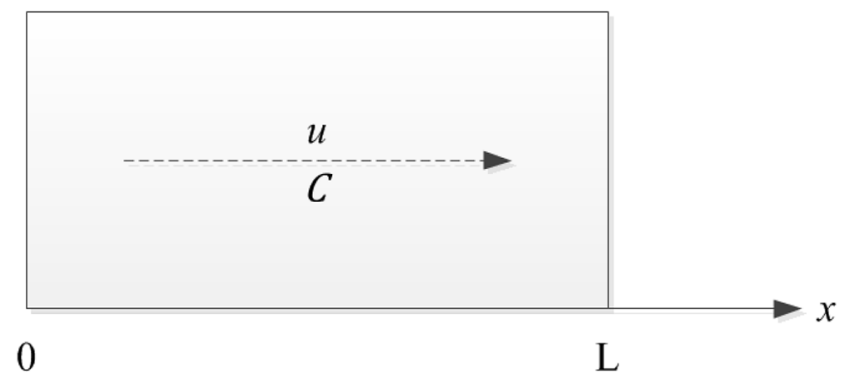

Fig. 1. The geometrical domain on one side of a facultative pond.



Fig. 2. The geometrical domain of the surface plane of facultative pond.

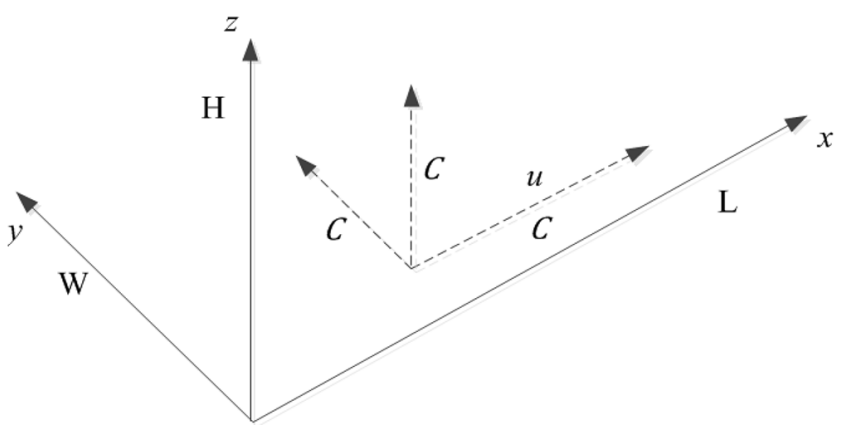

Fig. 3. The geometrical domain of interior space of facultative pond.

The representation of the advection-diffusion mechanism of the pollutant concentration with flow in one direction on one side of a facultative pond has been described by Sunarsih et al. [31] by the following equation:

$$
\frac{\partial \mathrm{C}}{\partial \mathrm{t}}=-\frac{\partial(\mathrm{uC})}{\partial \mathrm{x}}+\mathrm{D}_{\mathrm{mx}} \frac{\partial^{2} \mathrm{C}}{\partial \mathrm{x}^{2}}
$$

The following equation is applicable for the surface plane of facultative pond [32]:

$$
\frac{\partial \mathrm{C}}{\partial \mathrm{t}}=-\frac{\partial(\mathrm{uC})}{\partial \mathrm{x}}+\mathrm{D}_{\mathrm{mx}} \frac{\partial^{2} \mathrm{C}}{\partial \mathrm{x}^{2}}+\mathrm{D}_{\mathrm{my}} \frac{\partial^{2} \mathrm{C}}{\partial \mathrm{y}^{2}}
$$

Then, taking account the one-directional flow, the depth of the pond is measured as follows [11]:

$$
\frac{\partial \mathrm{C}}{\partial \mathrm{t}}=-\frac{\partial(\mathrm{uC})}{\partial \mathrm{x}}+\mathrm{D}_{\mathrm{mx}} \frac{\partial^{2} \mathrm{C}}{\partial \mathrm{x}^{2}}+\mathrm{D}_{\mathrm{my}} \frac{\partial^{2} \mathrm{C}}{\partial \mathrm{y}^{2}}+\mathrm{D}_{\mathrm{mz}} \frac{\partial^{2} \mathrm{C}}{\partial \mathrm{z}^{2}} .
$$

Descriptions of $C, u, \mathrm{D}_{\mathrm{mx}}, \mathrm{D}_{\mathrm{my}}$ and $\mathrm{D}_{\mathrm{mz}}$ used in Eqs. (1)-(3) are given below:

$C \quad$ : concentration of BOD $\left(\mathrm{ML}^{-3}\right)$

$u$ : flow velocity $\left(\mathrm{LT}^{-1}\right)$

$\mathrm{D}_{\mathrm{mx}}$ : diffusion coefficient in direction $\left(\mathrm{L}^{2} \mathrm{~T}^{-1}\right)$

$\mathrm{D}_{\mathrm{my}}$ : diffusion coefficient in direction $\left(\mathrm{L}^{2} \mathrm{~T}^{-1}\right)$

$\mathrm{D}_{\mathrm{mz}}$ : diffusion coefficient in direction $\left(\mathrm{L}^{2} \mathrm{~T}^{-1}\right)$

Eq. (1)-(3) are known as the one-, two-, and three-dimensional (or, 1D, 2D, and 3D) advection-diffusion equations in one-way flow without reaction and settlement, respectively.

\subsection{Explicit Finite Difference Method}

The finite difference method is regularly used for solving technical 
and mathematical problems of physical phenomenon possessing regular geometries. The principle of this method involves replacing of the derivatives of differential equations with discretization of finite differences based on the Taylor series [33]. The explicit finite difference method means that the variables at a particular state of a system or a solution at stage in time can be utilized to determine the state of the system in the next time (Fig. 4).

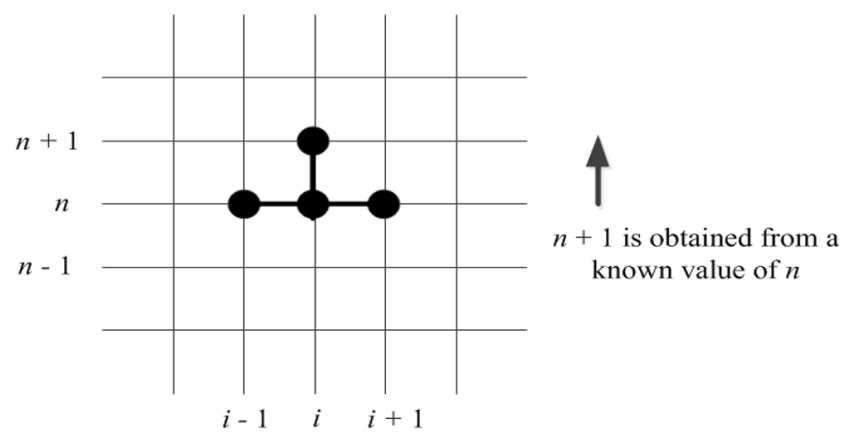

Fig. 4. Schematic diagram of explicit finite difference method.

In explicit finite difference method, the variable function of pollutant concentration $\mathrm{C}(x, t)$ and its derivatives in space and time are approximated in the following form [34]:

$$
\begin{gathered}
C(x, t)=C_{i}^{t} \\
\frac{\partial \mathrm{C}(\mathrm{x}, \mathrm{t})}{\partial \mathrm{t}}=\frac{\mathrm{C}_{\mathrm{i}}^{\mathrm{t}+1}-\mathrm{C}_{\mathrm{i}}^{\mathrm{t}}}{\Delta \mathrm{t}} \\
\frac{\partial \mathrm{C}(\mathrm{x}, \mathrm{t})}{\partial \mathrm{x}}=\frac{\mathrm{C}_{\mathrm{i}+1}^{\mathrm{t}}-\mathrm{C}_{\mathrm{i}-1}^{\mathrm{t}}}{\Delta \mathrm{x}} \\
\frac{\partial^{2} \mathrm{C}(\mathrm{x}, \mathrm{t})}{\partial \mathrm{x}^{2}}=\frac{\mathrm{C}_{\mathrm{i}+1}^{\mathrm{t}}-2 \mathrm{C}_{\mathrm{i}}^{\mathrm{t}}+\mathrm{C}_{\mathrm{i}-1}^{\mathrm{t}}}{\Delta \mathrm{x}^{2}}
\end{gathered}
$$

Explicit finite difference method can be applied to 1D, 2D, and $3 \mathrm{D}$ advection-diffusion models. The discretization of a pond is shown in Fig. 5.



Fig. 5. The discretization of a pond based on its depth level.
If the advection-diffusion model is on one side of pond (one-dimensional), then the discretization of pond can be seen as the red grid as shown in Fig. 5 (with $h=0 \mathrm{~m}$ ). The advection-diffusion model of a two-dimensional surface plane of a pond is also shown in Fig. 5 with $h=0 \mathrm{~m}$.

\section{Results and Discussions}

The advection-diffusion model was solved by discretization using explicit finite difference method. The discretization result was obtained by substituting Eqs. (1)-(3) with Eqs. (5)-(7). The discrete equations are as follows:

a. $1 \mathrm{D}$

$$
\frac{\mathrm{C}_{\mathrm{i}}^{\mathrm{t}+1}-\mathrm{C}_{\mathrm{i}}^{\mathrm{t}}}{\Delta \mathrm{t}}=-u \frac{\mathrm{C}_{\mathrm{i}+1}^{\mathrm{t}}-\mathrm{C}_{\mathrm{i}-1}^{\mathrm{t}}}{2 \Delta \mathrm{x}}+D_{m x} \frac{\mathrm{C}_{\mathrm{i}+1}^{\mathrm{t}}-2 \mathrm{C}_{\mathrm{i}}^{\mathrm{t}}+\mathrm{C}_{\mathrm{i}-1}^{\mathrm{t}}}{\Delta x^{2}}
$$

b. $2 \mathrm{D}$

$$
\begin{gathered}
\frac{\mathrm{C}_{\mathrm{i}, \mathrm{j}}^{\mathrm{t}+1}-\mathrm{C}_{\mathrm{i}, \mathrm{j}}^{\mathrm{t}}}{\Delta \mathrm{t}}=- \\
-u \frac{\mathrm{C}_{\mathrm{i}+1, \mathrm{j}}^{\mathrm{t}}-\mathrm{C}_{\mathrm{i}-1, \mathrm{j}}^{\mathrm{t}}}{2 \Delta \mathrm{x}}+D_{m x} \frac{\mathrm{C}_{\mathrm{i}+1, \mathrm{j}}^{\mathrm{t}}-2 \mathrm{C}_{\mathrm{i}, \mathrm{j}}^{\mathrm{t}}+\mathrm{C}_{\mathrm{i}-1, \mathrm{j}}^{\mathrm{t}}}{\Delta x^{2}}+ \\
D_{m y} \frac{\mathrm{C}_{\mathrm{i}, \mathrm{j}+1}^{\mathrm{t}}-2 \mathrm{C}_{\mathrm{i}, \mathrm{j}}^{\mathrm{t}}+\mathrm{C}_{\mathrm{i}, \mathrm{j}-1}^{\mathrm{t}}}{\Delta y^{2}}
\end{gathered}
$$

c. $3 \mathrm{D}$

$$
\begin{aligned}
& \frac{\mathrm{C}_{\mathrm{i}, \mathrm{j}, \mathrm{k}}^{\mathrm{t}+1}-\mathrm{C}_{\mathrm{i}, \mathrm{j}, \mathrm{k}}^{\mathrm{t}}}{\Delta \mathrm{t}}=-u \frac{\mathrm{C}_{\mathrm{i}+1, \mathrm{j}, \mathrm{k}}^{\mathrm{t}}-\mathrm{C}_{\mathrm{i}-1, \mathrm{j}, \mathrm{k}}^{\mathrm{t}}}{2 \Delta \mathrm{x}}+ \\
& D_{m x} \frac{\mathrm{C}_{\mathrm{i}+1, \mathrm{j}, \mathrm{k}}^{\mathrm{t}}-2 \mathrm{C}_{\mathrm{i}, \mathrm{j}, \mathrm{k}}^{\mathrm{t}}+\mathrm{C}_{\mathrm{i}-1, \mathrm{j}, \mathrm{k}}^{\mathrm{t}}}{\Delta x^{2}}+ \\
& D_{m y} \frac{\mathrm{C}_{\mathrm{i}, \mathrm{j}+1, \mathrm{k}}^{\mathrm{t}}-2 \mathrm{C}_{\mathrm{i}, \mathrm{j}, \mathrm{k}}^{\mathrm{t}}+\mathrm{C}_{\mathrm{i}, \mathrm{j}-1, \mathrm{k}}^{\mathrm{t}}}{\Delta y^{2}}+D_{m z} \frac{\mathrm{C}_{\mathrm{i}, \mathrm{j}, \mathrm{k}+1}^{\mathrm{t}}-2 \mathrm{C}_{\mathrm{i}, \mathrm{j}, \mathrm{k}}^{\mathrm{t}}+\mathrm{C}_{\mathrm{i}, \mathrm{j}, \mathrm{k}-1}^{\mathrm{t}}}{\Delta z^{2}} \\
& C_{i}^{t+1}=C_{i-1}^{t}\left[\frac{u \Delta t}{2 \Delta x}+\frac{D_{m x} \Delta t}{\Delta x^{2}}\right]+C_{i}^{t}\left[1-2 \frac{D_{m x} \Delta t}{\Delta x^{2}}\right]+ \\
& C_{i+1}^{t}\left[-\frac{u \Delta t}{2 \Delta x}+\frac{D_{m x} \Delta t}{\Delta x^{2}}\right] \\
& C_{i, j}^{t+1}=C_{i-1, j}^{t}\left[\frac{u \Delta t}{2 \Delta x}+\frac{D_{m x} \Delta t}{\Delta x^{2}}\right]+ \\
& C_{i, j}^{t}\left[1-2 \frac{D_{m x} \Delta t}{\Delta x^{2}}-2 \frac{D_{m y} \Delta t}{\Delta y^{2}}\right]+ \\
& C_{i, j+1}^{t}\left[\frac{D_{m y} \Delta t}{\Delta y^{2}}\right]+C_{i, j-1}^{t}\left[\frac{D_{m y} \Delta t}{\Delta y^{2}}\right]+C_{i+1, j}^{t}\left[-\frac{u \Delta t}{2 \Delta x}+\frac{D_{m x} \Delta t}{\Delta x^{2}}\right] \\
& C_{i, j, k}^{t+1}=C_{i-1, j, k}^{t}\left[\frac{u \Delta t}{2 \Delta x}+\frac{D_{m x} \Delta t}{\Delta x^{2}}\right]+ \\
& C_{i, j, k}^{t}\left[1-2 \frac{D_{m x} \Delta t}{\Delta x^{2}}-2 \frac{D_{m y} \Delta t}{\Delta y^{2}}-2 \frac{D_{m z} \Delta t}{\Delta z^{2}}\right]+ \\
& C_{i, j+1, k}^{t}\left[\frac{D_{m y} \Delta t}{\Delta y^{2}}\right]+C_{i, j-1, k}^{t}\left[\frac{D_{m y} \Delta t}{\Delta y^{2}}\right]+ \\
& C_{i+1, j, k}^{t}\left[-\frac{u \Delta t}{2 \Delta x}+\frac{D_{m x} \Delta t}{\Delta x^{2}}\right]+C_{i, j, k+1}^{t}\left[\frac{D_{m z} \Delta t}{\Delta z^{2}}\right]+ \\
& C_{i, j, k-1}^{t}\left[\frac{D_{m z} \Delta t}{\Delta z^{2}}\right]
\end{aligned}
$$


With the help of pollutant concentration value at time $(t)$, at a given grid-point, Eqs. (11)-(13) are used to calculate the pollutant concentration value at $t+1$. The equation can be solved using MATLAB software by providing the parameter values. These parameters are the diffusion coefficient, flow velocity, and flow time. The parameters were determined by utilizing data obtained from field samples at the Sewon WWTP. The value of diffusion coefficient parameter was $D_{m x}=D_{m y}=D_{m z}=8.23 \times 10^{-5} \mathrm{~m}^{2} / \mathrm{h}$ (the diffusion coefficients of the $x, y$, and $z$ directions are assumed to be the same). The diffusion coefficient parameters were estimated using Eyring's theory and the hydrodynamic theory of the Stokes-Einstein equation [35]. The flow velocity was $u=1.0875 \mathrm{~m} / \mathrm{h}$ and the flow time was $t=24 \mathrm{~h}$. The size of the facultative pond was. Based on the size of the pond, the grids were of specific sizes, such as $\triangle x 1=11, \triangle x 2=27.5, \triangle y 1=10, \triangle y 2=25$, and $\triangle h=1$.

Based on the advection-diffusion mechanism, the pollutant concentration or BOD value is calculated using explicit finite difference methods that are applied to the MATLAB software. The results of these calculations are simulated in the form of $2 \mathrm{D}$ graphics, which is also produced using the MATLAB software.

The simulation of the BOD concentration distribution based on the advection-diffusion mechanism for one (length) side of a facultative pond is shown in Fig. 6. It can be shown that, at $t$ $=1$, the highest BOD concentration was at the center of the length side of the pond. To the left and right of the midpoint, the BOD concentration decreases. However, BOD concentrations on the left show a tendency to decrease more significantly than on the right. As the aerator was situated at the midpoint of the length side of the pond, the BOD concentration was lower in the left and right directions of the pond length. The BOD concentration was only being examined on one side of the pond. As a result, the distribution of BOD concentrations (Fig. 6) does not appear clearly for any particular point in time.

BOD concentrations decrease over time, but the direction of the BOD distribution increases continually. The value of BOD decreases with an increase in the spread of BOD. This can be observed from the data displayed at the cursor. At the same value of $\mathrm{X}$ (length of the pond) for the different values of Y (time), the BOD concentrations appear altered. At $t=6$, the concentration value of BOD were 75 and 96 . At $t=19$, it had decreased to 59 and 38. At $t=19$, highest BOD concentration was located at the right of the length side of the pond. This occurred as a result of movement of mass (advection), accompanied by spread of mass (diffusion).

Fig. 6 can also be regarded as a simulation of 1D advection-diffusion model. The simulation of the 1D advection-diffusion model of the pond can also be performed on the width side of the pond as shown in Fig. S1.

Similar to the length side, at $t=6$, the highest BOD concentration was in the center of the width side of the pond. To the left and right of the midpoint, the BOD concentration decreased. However, BOD concentrations on the left ended to decrease more drastically than on the right. There is an aerator in the middle of the pond; so, the BOD concentration is lower to the left and right of the width side of the pond.

BOD concentrations on the width side of the pond also decreased over time. This is seen from the data shown at the cursor. At

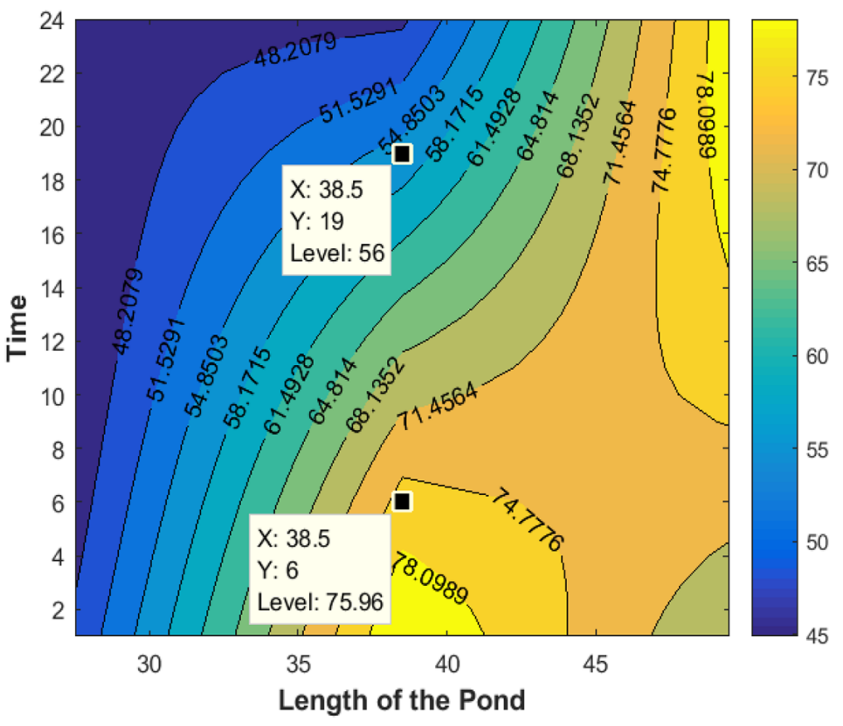

Fig. 6. Distribution of $\mathrm{BOD}$ on the length side of the pond.

$t=6$, the BOD concentration value at the point on the side of the pond was 46.02, decreases at $t=19$, and becomes 43.55. At $t=19$, the highest BOD concentration was located on the left hand side of the width of the pond. This occurred as a result of movement of mass (advection), accompanied by spread of mass (diffusion).

Based on the observations made from Figs. 6 and S1, it could be concluded that the highest BOD concentration was at the middle of the pond. Over time, though, the concentration of BOD spreads and decreases. The spread in BOD concentration was also accompanied by the process of mass transfer from one position to another enabling concentration of BOD to increase at a particular point. The simulation of the BOD concentration distribution is based on the advection-diffusion mechanism for a facultative pond surface plane as shown in Figs. S2 and S3. At $t=6$, the highest BOD concentration is in the middle of the surface plane of the pond. The nearer to the edge of the pond, the lower is the BOD concentration. This was attributed to the role of the aerator. The distribution of BOD concentration across the surface plane of the pond becomes transparent for some time.

At $t=19$, the highest BOD concentration was located in the middle of the surface edge of the pond. The more toward the middle of the pond, the lower is the BOD concentration. BOD concentrations at the left edge of the surface plane of the pond succeed in possessing the standard minimum quality values. These are the variety of factors, including the aerator, temperature, $\mathrm{pH}$, and the season over long time intervals.

From Figs. S2 and S3, it can be concluded that the process of spreading and mass transfer took place over a duration of 13 h. Mass spread (diffusion) causes a decrease in BOD concentration. This is evident from the cursor data shown in Figs. S2 and S3. At the same point or at the position of the pond plane, the BOD concentration level decreases from 55.29 at $t=6$ to 54.47 at $t$ $=19$. However, this decrease in BOD concentration was only about $0.82 \mathrm{mg} / \mathrm{L}$ over the span of $13 \mathrm{~h}$.

Mass transfer (advection) caused an increase in BOD 
concentration. This was evident on the right side of Figs. S2 and S3. The yellow color which indicates the highest concentration was not originally present on the right-hand side of Fig. S2, but it appears on the right-hand side of Fig. S3. The simulation of BOD concentration distribution based on the advection-diffusion mechanism at a pond depth of one meter is shown in Figs. S4 and S5.

The interpretations of Figs. S4 and S5 are similar to those provided earlier for Figs. S2 and S3, primarily because each or the four figures display equal advection-diffusion in a pond at the same time. However, there is a difference between the figures, and this difference is with respect to the level of BOD concentration. Therefore, spreading directions look slightly different. Figures S4 and S5 have higher BOD concentration levels than Figs. S2 and S3. This can be seen from the cursor data shown in Fig. S2, which shows BOD concentration level of 55.29, while Fig. S4 shows 59.26. The concentration level of BOD in Fig. S3 is 54.47; in Fig. S5, the concentration level of BOD is 60.65.

The increase in BOD concentrations, as shown in Figs. S4 and S5, was due to the different depths of the pond. Figs. S2 and S3 illustrate advection-diffusion on the surface plane of the pond (at a depth of meters). So, the depth of the pond is insignificant and can be disregarded. Figs. S4 and S5 illustrate advection-diffusion on a plane of ponds with a depth of one meter. Increased BOD concentrations at higher pond depths are due to decreasing sunlight; photosynthesis would not happen efficiently due to the increased BOD concentrations. Also, the diffusion of oxygen at the surface of the pond is difficult to achieve certain depth. Aerators work more slowly at a depth of the pond; so, the oxygen delivery in wastewater is also decreasing. Therefore, the level of oxygen demand in wastewater would be higher.

The numerical results illustrated in Figs. 6 and S1-S5 are compared with data obtained in the field. The results obtained are the correlation for the $1 \mathrm{D}$ model of -0.98 , the $2 \mathrm{D}$ model of -0.51 , and the 3D model of -0.30 . The correlation results show that the numerical results obtained from $2 \mathrm{D}$ and $3 \mathrm{D}$ models are non-significant. This happens because the model focuses only on one-way flow, from the inlet to the outlet ( direction). The numerical results data and field data of 1D, 2D, and 3D models can be illustrated in Fig. S6.

\section{Conclusions and Future Works}

The advection-diffusion mechanism in a facultative pond could be described by a series of mathematical equations that functions by considering the geometrical domain of facultative ponds. The geometrical domain of the facultative ponds consists of the sides, the surface planes, and the interior space.

At the side of the pond, the highest BOD concentration is found at its midpoint. However, over time, the BOD concentration spreads (diffusion) and decreases. The spread of BOD concentration is also accompanied by the process of mass transfer from one position to another (advection). Therefore, the BOD concentration increased at a particular point. However, advection-diffusion at the side of the pond was not apparent at any point.

In contrast to what happens on the side of the pond, advection-diffusion was apparent at the surface plane of the facultative pond.
The level of BOD concentration in a plane of the pond would be seen increasing if the attention was paid to the depth. The deeper the pond, the higher the BOD concentration of the wastewater is. It was believed that this occurred due to reduced sunlight, oxygen diffusion from the surface of the pond, and the work of the aerator at the depth of the pond. Therefore, it can be concluded that the more complex of geometrical domain of a facultative pond, the more apparent is the process of advection-diffusion occurrence in the pond.

In the future researches, it is recommended to optimize the pollutant degradation in the ponds. Some mathematical optimization models will be formulated to determine the optimal decision by minimizing some objective function using an optimization algorithm.

\section{Acknowledgment}

Thanks to the Leaders and staff WWTP Sewon, Public Works Department, Housing and ESDM Local Government Yogyakarta Indonesia who have given permission for the research and data collection quality control wastewater WWTP Sewon. Thanks for fund supported of the Ministry of Research, Technology and Higher Education (Kemenristekdikti) through research grant Featured Basic Research in University (PDUPT) No. 10116/UN7.P4.3/PP/2018.

\section{Author Contributions}

S.S. (Associate Professor) conducted to be responsible all research activities. D.P.S. (Associate Professor) conducted to be describes the theory process of Advection-Diffusion in the stabilization ponds. G.A.P. (research assistant) help with data collection, the process simulating and validating data. S.S. (Ph.D. Student) conducted to be formulated mathematics, creating programs, simulating and validating data, H.H. (Professor) conducted final preparation and checking manuscript.

\section{References}

1. Martinez FC, Cansino AT, Garcia MAA, et al. Mathematical Analysis for the Optimization of a Design in a Facultative Pond: Indicator Organism and Organic Matter. Math. Prob. Eng. 2014;2014:1-12

2. James A. An Introduction to Water Quality Modelling. $2^{\text {nd }}$ ed. England: John Wiley \& Sons; 1993. p. 80-81.

3. Jha R, Bryant S, Lake L. Effect of Diffusion on Dispersion. Soc. Pet. Eng. J. 2011;16:65-77.

4. Gloyna EF. Waste Stabilization Ponds. Geneva: World Health Organization; 1971. p. 45-48.

5. Jinjaruk T, Chunkao K, Pongput K, et al. HDPE Pipeline Length for Conditioning Anaerobic Process to Decrease BOD in Municipal Wastewater. Env. Asia. 2018;11(1):31-44.

6. Jinjaruk T, Maskulrath P, Choeihom C, et al. The Appropriate Biochemical Oxygen Demand Concentration for Designing Domestic Wastewater Treatment Plant. Env. Asia. 2019;12(1): 
162-168.

7. Noikondee R, Chunkao K, Bualert S, et al. Evaluation of Dissolved Oxygen Stratification in an Oxidation Pond for Community Wastewater Treatment through King's Royally Initiated "Nature by Nature" Process. Env. Asia. 2019;12(1): 169-177.

8. Kaya B, Gharehbaghi A. Implicit Solutions of Advection Diffusion Equation by Various Numerical Methods. Aust. J. Basic Appl. Sci. 2014;8(1):381-391.

9. Thongmoon M, McKibbin RA. Comparison of Some Numerical Methods for the Advection-Diffusion Equation. Res. Lett. Inf. Math. Sci. 2006;10:49-62.

10. Savovic S, Djordjevich A. Finite Difference Solution of the One-Dimensional Advection-Diffusion Equation with Variable Coefficients in Semi-Infinite Media. Int. J. Heat Mass Transf. 2012;55:4291-4294.

11. Dehghan M. Numerical solution of the three-dimensional advection-diffusion equation. Appl. Math. Comput. 2004;150:5-19.

12. Thongmoon M, McKibbin R, Tangmanee R. Numerical Solution of a 3-D Advection-Dispersion Model for Pollutant Transport. Thai J. Math. 2007;5(1):91-108.

13. Appadu AR, Djoko JK, Gidey HH. A computational study of three numerical methods for some advection-diffusion problems. Appl. Math. Comput. 2016;272:629-647.

14. Brewitt-Taylor CR, Weaver JT. On the finite difference solution of two-dimensional induction problems. Geophys J. R. astr. SOC. 1976;47:375-396.

15. Patil HM, Maniyeri R. Finite difference method based analysis of bio-heat transfer in human breast cyst. Therm. Sci. Eng. Prog. 2019;10:42-47.

16. Gao L, Keyes D. Combining finite element and finite difference methods for isotropic elastic wave simulations in an energy-conserving manner. J. Comput. Phys. 2019;378:665-685.

17. Ben-romdhane $\mathrm{M}$, Temimi $\mathrm{H}$, Baccouch $\mathrm{M}$. An iterative finite difference method for approximating the two-branched solution of Bratu's problem. Appl. Numer. Math. 2019;139:62-76.

18. Arteaga A, Guevara J. A Conservative Finite Difference Scheme for Static Diffusion Equation. Divul. Mat. 2008;16:39-54.

19. Kamyabi A, Kermani V, Kamyabi M. Engineering Analysis with Boundary Elements Improvements to the meshless generalized finite difference method. Eng. Anal. Bound. Elem. 2019;99:233243.

20. Indika U, Malin P, Ivan DR, et al. Unified perfectly matched layer for finite-difference time-domain modeling of dispersive optical materials. Opt. Express 2009;17:21179-21190.

21. Lei J, Xu Y, Gu Y, Fan C. The generalized finite difference method for in-plane crack problems. Eng. Anal. Bound. Elem. 2019;98: 147-156.
22. Jeong D, Kim J. Fast and accurate adaptive finite difference method for dendritic growth. Comput. Phys. Commun. 2019;236:95-103.

23. Fan C, Chu C, Li T. Numerical solutions of waves-current interactions by generalized finite difference method. Eng. Anal. Bound. Elem. 2019;100:150-163.

24. Chen J, Gu Y, Wang MC, et al. Application of the generalized finite difference method to three-dimensional transient electromagnetic problems. Eng. Anal. Bound. Elem. 2018;92:257-266.

25. Sunarsih, Purwanto, Budi WS. Mathematical modeling regime steady state for domestic wastewater treatment facultative stabilization ponds. J. Urban Environ. Eng. 2013;7(2):293-301.

26. Sunarsih, Sasongko DP, Sutrisno. Mathematical Model of Biological Oxygen Demand in Facultative Wastewater Stabilization Pond Based on Two-Dimensional AdvectionDispersion Model. Amer. J. Eng. Res. 2016;5(11):1-5.

27. Sunarsih, Purwanto, Budi WS. Modeling of Domestic Wastewater Treatment Facultative Stabilization Ponds. Int. J. Technol. 2015;4:689-698.

28. Sunarsih, Sasongko DP. Sutrisno. Distribution Model 1-D of Concentration on Chemical Oxygen Demand in Waste Stabilization Ponds. Adv. Sci. Lett. 2017;23(3):2383-2385.

29. Sunarsih, Farikhin, Rya $\mathrm{H}$, et al. Numerical Solution of Distribution Model 2-D of Concentration on Chemical Oxygen Demand in Waste Stabilization Ponds. Adv. Sci. Lett. 2017;23(3): 2273-2276.

30. Gitta AP, Sunarsih, Susilo H. Numerical simulation of advection-diffusion on flow in waste stabilization ponds (1-dimension) with finite difference method forward time central space scheme. Environ. Eng. Res. 2018;23(4):442-448.

31. Sunarsih, Sasongko DP, Sutrisno. Mathematical Model of Biological Oxygen Demand in Facultative Wastewater Stabilizations Ponds Based on Two-Dimensional AdvectionDispersion Model Facultative Ponds Stabilization Ponds. Am. J. Eng. Res. 2016;5:01-05.

32. Jha BK, Adlakha N, Mehta MN. Analytic Solution of Two Dimensional Advection Diffusion Equation Arising In Cytosolic Calcium Concentration Distribution. Int. Math. Forum. 2012; 7(3):135-144.

33. Igboekwe MU, Achi NJ. Finite Difference Method of Modelling Groundwater Flow. J. Water Resour. Prot. 2011;3:192-198.

34. Sousa EA. Second order explicit finite difference method for the fractional advection diffusion equation. Comput. Math. Appl. 2012;64:3141-3152.

35. Welty JR., Wicks CE., Wilson RE. Fundamentals of Momentum, Heat and Mass Transfer. 5th ed., John Wiley \& Sons, 2000, p.50-60 